\title{
Análise documental na Museologia: um breve exercício de identifi- cação de conceitos
}

\author{
Documentary analysis in Museology: brief study the identification of concepts
}

\author{
Mateus da Silva Reis \\ Mestrando em Ciência da Informação \\ Universidade Federal do Pará \\ mateusreis42@hotmail.com \\ João Batista Ernesto de Morais \\ Doutor em Estudos Literários \\ Universidade Estadual Paulista Júlio de Mesquita Filho \\ jota@marili.unesp.br \\ Thiago Henrique Bragato Barros \\ Doutor em Ciência da Informação \\ Universidade Federal do Rio Grande do Sul \\ sean.vogel@gmail.com
Roberto Lopes dos Santos Junior
Doutor em Ciência da Informação Universidade Federal do Pará bobblopes@hotmail.com

\begin{abstract}
Resumo
O presente estudo buscou identificar os conceitos de Análise Documental na Museologia, observando de que forma aquela atua na análise do conteúdo documental em caráter museológico. A pesquisa discutiu as etapas de cunho analítico e sintético deste procedimento, os seus objetivos em relação ao tratamento documental em museus, além de noções sobre documentação museológica. A pesquisa utilizou, como base, textos e artigos ligados à Museologia que lidam, direta ou indiretamente, sobre o tema da Análise Documental, a partir do registro e organização das informações (leituras documentárias, descrição, classificação) dos acervos museológicos. A pesquisa identificou que a temática ligada a relação entre a Análise Documental e documentação museológica apresenta um promissor campo de estudo, sendo identificado a importância da continuação de pesquisas que lidam sobre o tema, permitindo maior aprimoramento teórico e prático dos museólogos em relação a organização e representação da informação.
\end{abstract}

\section{Palavras-chave}

Análise Documental. Museologia. Documentação Museológica.

\begin{abstract}
The present research sought to identify the concepts of Documentary Analysis, a process that allows the treatment of documents in order to represent them, in Museology, aiming to observe how the Documental Analysis acts in the analysis of the documentary content in museological character. The research discusses the steps of analytical and synthetic nature of this procedure, what its objectives are in relation to documentary treatment in museums, as well notions about museological documentation. The research uses texts and articles related to Museology that deal, directly or indirectly, on the subject of Documentary Analysis, and the registration and organization of the information (doc-
\end{abstract}


umentary readings, description, classification) in museological collections. The research identified that the thematic about the relationship between Documentary Analysis and museological documentation presents a promising field of study, potentialize the importance of the continuation of researches about the theme, allowing more theoretical and practical improvement to the information organization and representation in museums.

\section{Keywords}

Documentary analysis. Museology. Museological Documentation.

\section{INTRODUÇÃO}

A Análise Documental é definida como o processo de estudo, síntese e representação, objetivando o reconhecimento das características de forma e conteúdo do documento (BOCCATO; FUJITA, 2006). Este processo também é definido como um tratamento documental, tendo como finalidade a criação de produtos de representação, como resumos e índices (FUJITA; NARDI; SANTOS, 1998). Nesse procedimento, derivam-se os conceitos de análise de forma e de conteúdo, no qual a primeira preocupa-se com a descrição bibliográfica do documento e a segunda com a descrição de aspectos intrínsecos, de acordo com a temática do documento (GUIMARÃES; MORAES; GUARIDO, 2007). Ao tratarem de Análise Documental de Conteúdo, Guimarães, Moraes e Garrido (2007) destacam também a natureza analíticosintética do processo, reforçando a etapa de síntese como meio para a condensação e representação das linguagens documentais, com intuito de garantir uma rápida recuperação informacional.

No âmbito museológico, a Análise Documental se faz presente no eixo da documentação museológica, considerada um dos eixos que compõem a Museologia enquanto disciplina, que objetiva o registro, a organização e a representação das informações presentes no objeto musealizado ${ }^{1}$. Para Ferrez (1994), o processo de documentação museológica é interpretado como um catalisador, transformando o conteúdo do objeto em instrumentos que permitam a transmissão do conhecimento. Deste modo, compreende-se que a documentação museológica produz registros que permitem o controle e o acesso dos acervos em museus (CERAVOLO; TÁLAMO, 2000).

Ao tentar discutir a forma e o conteúdo dos documentos de museu, deve-se primeiro atentar ao fato de que estes possuem suportes variados, além do papel ou superfícies bidimensionais. O documento museológico é produzido a partir do processo de musealização ${ }^{2}$, naquilo que pode ser conhecido como uma "[...] valorização seletiva, mas contínua no conjunto de ações que visa à transformação do objeto em documento." (CURY, 2005, p. 25).

$O$ documento pode ser qualquer coisa material, desde que contenha um novo significado para o contexto museológico. Definir neste ponto a forma e o conteúdo de um documento de museu torna-se um desafio, dependendo de qual seja seu suporte. Entretanto, neste trabalho, para melhor identificação da Análise Documental na Museologia, opta-se por afirmar que a forma diz respeito a toda característica intrínseca do objeto museológico, conceituada como as dimensões físicas do documento, e o conteúdo refere-se à característica extrínseca do objeto, como seu contexto, trajetória ou estilo.

\footnotetext{
${ }^{1} \mathrm{O}$ objeto musealizado, ou museália, é um objeto que pode ser interpretado como "[...] qualquer tipo de realidade em geral." (DESVALLÉES; MAIRESSE, 2013, p. 68).

${ }^{2}$ A Musealização é um processo de transformação do objeto comum em objeto de museu, a partir das etapas da aquisição, pesquisa, conservação, documentação e comunicação, ou difusão do objeto (CURY, 2005).
} 
$\mathrm{Na}$ investida em identificar estes conceitos, alguns processos tornam-se perceptíveis no meio museológico. As etapas relacionadas às funções de análise e síntese, como a leitura técnica e a seleção de conceitos, são rapidamente reconhecidas pelos museólogos que possuem proximidade com a documentação museológica. No entanto, a função de representação torna-se uma operação turva no âmbito da Museologia, às vezes irreconhecível, às vezes localizáveis. Desta forma, compreende-se que o exercício de identificar as propriedades da Análise Documental na Museologia torna-se cabível, a partir da percepção de cada documentalista de museu (GUIMARÃES; MORAES; GUARIDO, 2007).

Com enfoque na Análise Documental direcionada ao conteúdo, buscam-se reconhecer, neste estudo, as etapas do processo analítico-sintético desse tipo de análise, em especial as apresentadas por Guimarães, Moraes e Guarido (2007), dentro dos procedimentos de documentação museológica, ilustrados pelas noções de Padilha (2014) e Camargo-Moro (1986). A pesquisa justifica-se na inquietação em reconhecer o papel da Análise Documental no meio museológico, no qual contém práticas e etapas semelhantes às encontradas naquela atividade, mas não diretamente associadas à área.

\section{PROCEDIMENTOS METODOLÓGICOS}

Trata-se de um estudo de natureza descritiva e bibliográfica. A pesquisa inicialmente realizou análise sobre os conceitos e etapas que identificam a Análise Documental. Posteriormente, foram identificadas noções que delineiam a documentação museológica e, por fim, foram listadas práticas de Análise Documental que podem ser inseridas no âmbito da documentação museológica. Conforme afirmado acima, utilizaram-se os estudos de Guimarães, Moraes e Guarido (2007), Padilha (2014) e Camargo-Moro (1986) para o direcionamento desta pesquisa e para o processo de identificação. A escolha do estudo de Guimarães, Moraes e Guarido (2007) caracteriza-se pela objetividade e compreensão dos autores ao descreverem o processo de Análise Documental. A seleção das obras de Camargo-Moro (1986) e Padilha (2014) justifica-se pela consideração de que ambos os estudos são marcos referenciais para o entendimento da documentação em museus.

\section{ANÁLISE DOCUMENTAL: CONCEITOS E ETAPAS}

Com a expressão oficialmente conceituada por Jean-Claude Gardin, em 1981, a Análise Documental, ou Documentária ${ }^{3}$, surgiu com a premissa de propor a representação de um documento, partindo de um processo de análise e síntese. Conforme Fujita, Nardi e Santos (1998), este processo elucida a uma desestruturação do conteúdo de um documento, para a criação de um novo produto documentário. As autoras apontam que o processo de Análise Documental funciona de forma sequencial e ordenada, a partir das seguintes operações:

ANÁLISE: leitura e segmentação do texto para identificação e seleção dos conceitos;

SÍNTESE: construção do texto documentário com os conceitos selecionados: enunciado de assunto e resumo;

REPRESENTAÇÃO: a representação possui duas naturezas distintas: na primeira, a representação é construída através de um processo de condensação intensiva do texto original, gerando os diferentes tipos de resumo; na segunda, a representação

\footnotetext{
${ }^{3}$ Ambas as grafias estão corretas, todavia, optou-se por utilizar para este estudo a grafia "Análise Documental", a fim de padronização.
} 
é realizada através do uso de uma Linguagem documentária [...] (FUJITA; NARDI; SANTOS, 1998, p. 21).

Visando a representação do conteúdo e a concepção de produtos, a Análise Documental também é considerada como um processo cognitivo e intelectual. Chaumier (1979, p. 13, apud MOLINA, 1989, p. 327, tradução livre), afirma que a Análise Documental é "[...] uma operação intelectual mais ou menos complicada, dependendo do grau de elaboração, e o seu resultado será o nascimento de diversos produtos secundários." Deste modo, compreende-se que a concepção destes instrumentos documentários advém de um conhecimento prévio do documentalista, ou indexador, a respeito do conteúdo do documento.

Para Kobashi (1996), a Análise Documental, quanto operação, transforma o conteúdo, ou texto-base, em dois tipos de representação: o resumo e o índice. Estes produtos definem-se de forma distinta, a partir das noções apresentadas pela autora. A indexação, segundo Kobashi, se caracteriza pela máxima condensação do texto-base, resultando em uma fragmentação dos conceitos e criação de palavras e sintagmas. Por outro lado, o resumo caracteriza-se pela sua aproximação com o texto-base, contendo uma "estrutura informacional" semelhante à sua origem. Pode-se afirmar que, diferente do resumo, os índices são mediados por "[...] um instrumento comutador - a linguagem documentária - que generaliza as informações do texto, integrando-o a 'classes' já previstas no referido instrumento." (KOBASHI, 1996, p. 9).

Os métodos e operações utilizados na Análise Documental partem da experiência e do "bom senso" dos documentalistas, para a criação de uma ou outra palavra-chave, buscando a recuperação do documento (CUNHA, 1987). Em seu estudo, Cunha (1987, p. 38) afirma que para a realização da análise, a Biblioteconomia e a Documentação utilizavam uma leitura de caráter único, fechado e universal. A referida autora também afirma que o processo de transformação de um texto original para alguma forma de representação é semântico, mesmo não seguindo uma regra ou padronização explícita. Todavia, mesmo que o analista da documentação trabalhe sob uma esfera empírico-pragmática, este deve considerar algumas variáveis para a realização da análise, sendo estas: o discurso, o idioma, a organização interna e a ideologia.

Na esfera da semiologia e semiótica, Lara (1993, p. 225) aponta que a preocupação da Análise Documental não é com o signo documentário em si, mas com "[...] o conjunto de reflexões que permita pensar teórica e operacionalmente a questão da construção e recepção do signo documentário." Esta complementa que são destacados dois momentos distintos na Análise Documental, a criação das Linguagens Documentárias ${ }^{4}$, e a utilização destas por usuários. À vista disso, compreende-se que a Análise Documental colabora com a dinâmica de sistemas de documentação e de recuperação de informações. Partindo da etapa da concepção da Linguagem Documentária, os analistas visam às necessidades do usuário.

Conforme Guimarães (2009), constata-se que o processo de Análise Documental, enquanto agente de fragmentação do conteúdo do documento e representação deste, apresenta finalidades bem definidas. Em vista disso, compreende-se que a "[...] concepção de AD reside na identificação, na descrição de etapas, para cujo desenvolvimento se utilizam de instrumentos e de onde decorre a geração de produtos." (GUIMARÃES, 2009, p. 111). Além

\footnotetext{
4 “As Linguagens Documentárias são consideradas metarrepresentações, ou representações documentárias, ao lado de outras formas de representação da informação, como resumos, catálogos, bibliografias, índices, inventários, repertórios, etc." (DODEBEI, 2002, p. 39).
} 
disso, o autor reitera que, com ênfase neste procedimento, ressalta-se a natureza cognitiva da Análise Documental.

Se a Análise Documental, além de ser uma experiência cognitiva, busca identificar e representar conteúdos pertencentes a documentos, é de se esperar que este processo se desdobre em outros procedimentos. Diante disso, surge em debate a questão da análise de conteúdo. Composta por um conjunto de técnicas que permitem destacar o conteúdo de documentos gravados/escritos, a Análise de Conteúdo "[...] pretende enfocar tanto a expressão como a coisa, independentemente da espécie de textos [...], desde que o analista suspeite que haja no conteúdo inferências úteis para o conhecimento dos homens que as produzem [...]" (CUNHA, 1987, p. 41-42). Dessa forma, conclui-se que esta tipologia de análise mergulha nas nuances do documento, além do que está registrado, levando em consideração a expressividade do autor.

Ao adentrar na esfera de discussão relacionada ao conteúdo, deve-se atentar à seguinte noção: o conteúdo do documento vai além das demarcações de registro onde, no entanto, segundo Lara (2001), sua definição é imprecisa. Com finalidade da Análise Documental em representar, é necessário considerar que o conteúdo deve ser representado. Para a referida autora,

É preciso verificar o que entendemos por conteúdo e que conteúdo representamos no contexto documentário quando utilizamos uma linguagem documentária. Assim como a segmentação de conteúdo feita por Marco Polo se fazia a partir de referências anteriores, no processo documentário "representar conteúdos" se relaciona a propósitos e concepções definidas de antemão. (LARA, 2001, p. 4).

A tentativa em definir o que é conteúdo resulta em consequências problemáticas. No entanto, deve-se considerar a interpretação do enunciador ao tentar representar o conteúdo, a partir do público-alvo a ser destinado. Em continuidade, a autora aponta:

A noção de conteúdo, portanto, não é simples. Sob a ótica do enunciador, a constituição de sistemas de informação para transferência é uma operação carregada de intencionalidade. A representação não tem um fim em si mesma, ao contrário, é uma construção que persegue objetivos específicos. Num determinado contexto uma vaca é um tipo de mamífero; noutro, um bicho sagrado e etc. [...] Conseqüentemente, um mesmo universo documental pode ser organizado e representado de diversas maneiras, pautando-se nos distintos propósitos a que se destinam. (LARA, 2001, p. 6).

O conteúdo pode ser moldável, conforme as intenções do enunciador para a indexação. À vista disso, entende-se que a noção do conteúdo não é universalmente um consenso, este se difere a partir de cada realidade em que está sendo analisado e de cada finalidade a ser representado.

Conforme afirmado acima, a Análise Documental é composta por etapas que permitem a análise, a síntese e a representação do conteúdo. Desta maneira, há uma concordância ao afirmar que o processo de Análise Documental é realizado a partir de uma operação analítico-sintética, partindo da fragmentação de conceitos e condensação destes para a criação de produtos documentários. Por outro lado, mesmo com esta concordância, algumas etapas tornam-se pouco claras para a compreensão deste processo. Com isso, utilizaram-se neste estudo as operações apontadas por Guimarães (2007), no qual este apresenta a Análise Documental de Conteúdo, conforme Figura 1. 
Figura 1 - Análise Documental: processo analítico-sintético

ETAPA ANALÍTICA

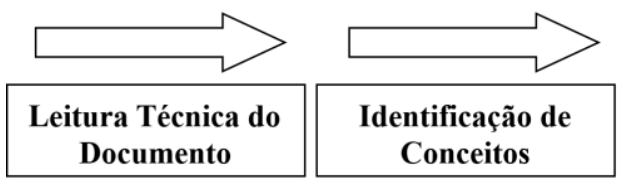

ETAPA SINTÉTICA

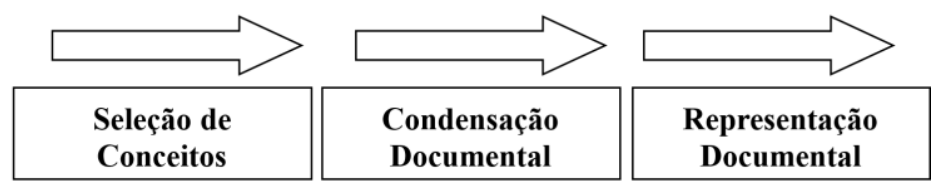

Fonte: Guimarães, Moraes e Guarido (2007) e Guimarães (2009).

Compreende-se, neste processo, a leitura documentária como primeira etapa. Esta é interpretada no momento em que o documentalista explora a estrutura do texto, buscando encontrar o conteúdo temático que define o documento, com base em um conjunto de estratégias metacognitivas ${ }^{5}$ (GUIMARÃES; MORAES; GUARIDO, 2007). Segundo Fujita (2004), a leitura documentária caracteriza o indexador como leitor profissional que realiza este procedimento. Deste modo, "O indexador torna-se um leitor no ato de análise de um documento com a finalidade de realizar a indexação para representação do conteúdo por meio de termos que serão, posteriormente, recuperados por um usuário do sistema de informação." (FUJITA, 2004, p.). Por seguinte, a autora aponta que a leitura documentária abarca três variáveis, sendo estas: o texto, referente à estrutura textual do documento; o leitor, ligado à imagem do indexador; e o contexto, referente à indexação do conteúdo em sistemas de recuperação. Além disso, Giasson (1993) aponta três fatores que envolvem a variável referente ao contexto no processo de leitura documentária, sendo estes os fatores psicológico, social e físico.

A segunda etapa refere-se à identificação dos conceitos presentes no documento. Neste momento, após a identificação das partes que definem a temática do documento, são construídos enunciados de assuntos. Com base na aplicação de um conjunto de categoriais conceituais, esta operação destaca-se pela formulação de termos relacionados diretamente ao conteúdo do documento.

Como primeira operação da etapa sintética, a seleção de conceitos está ligada à escoIha dos enunciados construídos na operação anterior. Segundo Guimarães, Moraes e Guarido (2007, p. 95), os "[...] enunciados de assunto são categorizados em principais, secundários e periféricos, e, por seguinte, ordenados logicamente, tendo como parâmetro a estrutura, a função e os usos (tipos de busca informacional ligados ao documento)." Compreendese que neste processo é dada maior importância aos termos principais encontrados pós análise da temática do documento.

As operações de Condensação Documental e Representação Documental incidem diretamente nas noções de Kobashi (1996) a respeito da construção de resumos e índices. Este primeiro procedimento se caracteriza pela redução do documento original, do texto base, para construção de um micro documento, enquanto o segundo se responsabiliza pela tradução do conteúdo temático do documento para a indexação, possibilitando a representação por meio dos índices (GUIMARÃES; MORAES; GUARIDO, 2007).

Este processo elucida como a dinâmica da Análise Documental funciona. Em vista disso, compreende-se que ela se inicia na leitura dos documentos, identificando as nuances que

\footnotetext{
${ }^{5}$ Conforme Ribeiro (2003, p. 109), metacognição está “[...] para além da cognição, isto é, a faculdade de conhecer o próprio ato de conhecer, ou, por outras palavras, consciencializar, analisar e avaliar como se conhece."
} 
compõem este, com base na experiência cognitiva e normas que regem esta operação. Entende-se também que o processo de Análise Documental se responsabiliza pela identificação dos conceitos do documento, além da seleção dos enunciados e a representação do conteúdo por meio dos produtos documentários.

Com a explicitação destas etapas, nota-se que é possível localizar estas em alguns campos científicos. Segundo Reis (2015, p. 40), a "Análise Documentária tem como objeto o texto e para expressar o seu conteúdo da melhor forma possível, ela se aproxima de outras áreas (disciplinas) com fins semelhantes". Com estas finalidades, a Análise Documental estabelece ligações com áreas que tratam o conteúdo documental, a fim de representá-lo, e se preocupam com a temática deste mesmo documento, como é o caso da Museologia, por intermédio da documentação museológica.

\section{NOÇÕES DE DOCUMENTAÇÃO MUSEOLÓGICA}

A documentação museológica é considerada uma das principais vertentes na gestão dos acervos em museus, responsável por organização, registro e mediação da informação (ROCHA, 2014). Partindo deste princípio, um museu deve, em uma de suas funções primárias, desenvolver e adotar métodos que possibilitem a documentação de suas coleções. Caso isto não seja possível, este não cumpre seu papel como instituição de promoção do conhecimento a partir da organização de suas coleções.

Para Camargo-Moro (1986), um museu que não possui suas informações atualizadas e em boas condições não está cumprindo com a função de preservação da memória. Deste modo, é possível compreender que um processo de documentação de acervos museológicos se define pela sua importância na coleta e sistematização de dados, onde estes são caracterizados pelas referências extrínsecas e intrínsecas do objeto salvaguardado. Segundo Yassuda $(2009$, p. 22) "[...] a documentação museológica representa um dos aspectos da gestão dos museus destinada ao tratamento da informação em todos os âmbitos, desde a entrada do objeto no museu até a exposição."

Compreende-se que o processo de documentação de um museu pode ser definido como um conjunto de técnicas que permitem registro, organização e mediação da informação. De acordo com Ferrez (1994), a documentação pode ser interpretada como um instrumento de transformação, catalisando as informações das coleções em dados para pesquisas científicas ou instrumentos de transmissão do conhecimento. Considerando o museu como uma instituição que preserva as coleções de "documentos físicos" e resulta em fontes de conhecimento a partir destes (MENSCH, 1992), o mesmo responsabiliza-se pela difusão das informações, com o auxílio de um sistema de documentação museológica.

Conceitua-se também a documentação museológica como responsável pelo fluxo e pela atualização dos dados que se referem aos objetos residentes no museu. Sob uma perspectiva tecnicista ${ }^{6}$, Ceravolo e Tálamo (2007) indicam que

[...] a função primordial da documentação é responder as organizações mantenedoras; os procedimentos documentários são técnicos e visam à elaboração e preenchimento de registros (registration), o armazenamento e a recuperação da informação. O "registrador" (registrar) deve criar, manter e responder pela custódia

\footnotetext{
${ }^{6}$ Em seu estudo, Ceravolo e Tálamo (2007) afirmam que a documentação em museus se divide em duas perspectivas distintas no tratamento da informação. A partir de suas concepções metodológicas, esta divisão se dá pela visão tecnicista, apoiada pelos norte-americanos, e a visão reflexiva, com o fator mais interpretativo, sustentada pelos europeus.
} 
dos objetos. Para isso ele deve estar preparado para fornecer informações atualizadas sobre o objeto, como sua localização e estado de conservação no interior das respectivas coleções. (CERAVOLO; TÁLAMO, 2007, p. 5).

À vista disso, reflete-se que a documentação dos acervos museológicos é o alicerce para os setores de pesquisa, comunicação, educação e salvaguarda das instituições museológicas. Fabbri (2010) afirma que não é possível desenvolver atividades dentro do museu se a documentação do acervo não estiver atualizada. Os procedimentos de registro e organização da informação de um acervo museológico também podem ser entendidos como instrumentos de salvaguarda. Deste modo, a preservação informacional torna-se uma etapa necessária para o futuro acesso à informação (SILVA, 2014).

Ademais, em uma compreensão da documentação museológica por meio de etapas, Padilha (2014) aponta que este processo se inicia pela seleção da peça, por meio dos processos de doação até a difusão da informação do objeto. Segundo Padilha (2014), o tratamento informacional dos acervos museológicos é realizado da seguinte maneira:

- selecionar - através das ações de aquisição por parte dos museus;

- pesquisar - a partir de uma análise das propriedades físicas, iconográficas, históricas e estilísticas do objeto;

- interpretar - interpretação do objeto sob um contexto histórico ou social;

- organizar - momento da descrição, classificação, produção de termos relacionados ao objeto;

- armazenar - formulação de acondicionamento para peça;

- disseminar - ação por intermédio do uso de termos ou palavras-chave relacionados ao objeto, a partir de um sistema de recuperação de informações;

- comunicar - a partir do uso de exposições, educação patrimonial e demais ações culturais, com base nas informações obtidas.

Observa-se que algumas etapas se desdobram em etapas secundárias. Como exemplo, o processo de organização abarca procedimentos mais específicos, como o processo de leitura visual do objeto museológico. A seguir, identificam-se as etapas de Análise Documental no âmbito da documentação em museus.

\section{IDENTIFICAÇÃO DAS ETAPAS DE ANÁLISE DOCUMENTAL NA DOCUMENTAÇÃO MUSEO- LÓGICA}

Pode-se afirmar que a Análise Documental pode ser identificada na documentação museológica? A resposta para a questão é talvez, visto que ambas as práticas são encaradas como uma forma de tratamento documental, com intuito de possibilitar a disseminação do conteúdo de seus documentos.

Ao tentar desenvolver uma identificação de conceitos, compreende-se que grande parte das etapas do processo analítico-sintético, elaborado por Guimarães, Moraes e Guarido (2007), reside na etapa de organização apontada por Padilha (2014). Em um exercício de observação, pode-se afirmar que as operações na Análise Documental presentes na Museologia são visualizadas nos itens a seguir: 


\section{a) Leitura Documentária}

Como primeira etapa, a leitura documentária propõe uma análise técnica do documento, a partir de fatores cognitivos e um conhecimento prévio. No âmbito museológico, a leitura documentária é realizada desde o primeiro contato com o objeto, buscando compreender as características físicas do objeto, independente do suporte. Em relação às normas, definir um procedimento padrão de leitura documentária para os objetos de museus tornase uma tentativa complexa. $O$ objeto de museu pode ser qualquer coisa, a partir de sua significação. Contudo, pode-se destacar um procedimento padrão prévio, com a leitura de pinturas, gravuras, desenhos, etc., registradas em um suporte bidimensional. Com base em experiências adquiridas com decorrer do tempo, a leitura documentária destes documentos pode ser realizada observando minuciosamente os detalhes da obra, começando pela parte superior, até a inferior, seguindo pela esquerda até a direita.

\section{b) Identificação de Conceitos}

Pós-leitura do documento, a identificação dos conceitos do documento museológico se realiza a partir de uma pesquisa deste. Qual sua definição? A que este se refere? Em que contexto ele se insere? Estas são perguntas comumente realizadas para reconhecer o conteúdo e conceito da obra. No caso de objetos históricos, torna-se fácil identificar suas propriedades. Deve-se levar em consideração também a quem o objeto pertenceu, indivíduo ou comunidade, fatores esses que devem ser destacados para a localização conceitual do documento.

\section{c) Seleção de Conceitos}

Ligada diretamente à identificação de conceitos, esta etapa tem por objetivo selecionar o que vai ser representado. No meio museológico, a seleção leva em consideração todas as propriedades do objeto, abarcando desde suas dimensões, localização, e a presença deste em alguma publicação cientifica. Contudo, esta etapa ainda respeita uma ordem de importância do que vai ser representado. Desta maneira, pode-se afirmar que os conceitos de classe primária se referem às propriedades históricas, características que apontam a presença do objeto em algum marco histórico de um determinado grupo ou comunidade: iconográficas, ligadas à iconografia do objeto, alguma personalidade ou algum símbolo que remeta às dimensões culturais, sociais ou políticas de uma sociedade; estilísticas, referentes ao estilo do objeto e comumente identificadas em pinturas, gravuras, esculturas, etc.; e sociais do objeto, referem-se às relações entre indivíduo e objeto, assim como as resignificações da peça. Por seguinte, a classe secundária abarca as características físicas, as marcas, as dimensões do objeto, etc. A classe secundária caracteriza-se pela forma do objeto, as propriedades físicas, como o tamanho e as incisões na superfície da peça. Por último, a classe terciária está ligada às características adicionais da obra, como a presença desta em alguma publicação cientifica.

\section{d) Condensação Documental}

A Condensação Documental tem por objetivo a criação de resumos e índices para a representação. Dentro da Documentação Museológica, este processo de síntese, pós- 
análise, é realizada na ficha catalográfica, a partir da descrição. A compressão do texto-base, ou documento-base, é executada como uma segunda leitura. Contudo, o resumo produzido engloba todos os conceitos de primeira classe, representando o máximo do conteúdo documental. No quesito de índices e terminologias, o Thesaurus ${ }^{7}$ para Acervos Museológicos ${ }^{8}$ é um dos principais exemplos.

\section{e) Representação Documental}

Como última etapa, a representação documental é realizada na etapa de disseminação na Documentação Museológica. O conteúdo documental dos acervos museológicos é representado por meio de terminologias, índices e resumos. Dessa maneira, a Museologia formula catálogos e estratégias que possibilitam o usuário realizar uma busca direta. Não há um formato padrão para a realização destes, cabendo a cada museu desenvolver suas estratégias de busca e de representação, com o apoio do Thesaurus.

Com base nos apontamentos acima, a Análise Documental na Museologia, por intermédio da Documentação Museológica, é identificada conforme Figura 2.

Figura 2 - Análise Documental na Museologia

ETAPA ANALÍTICA

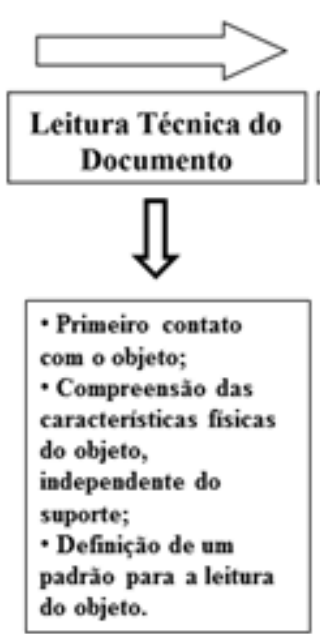

conceitos.
ETAPA SINTÉTICA
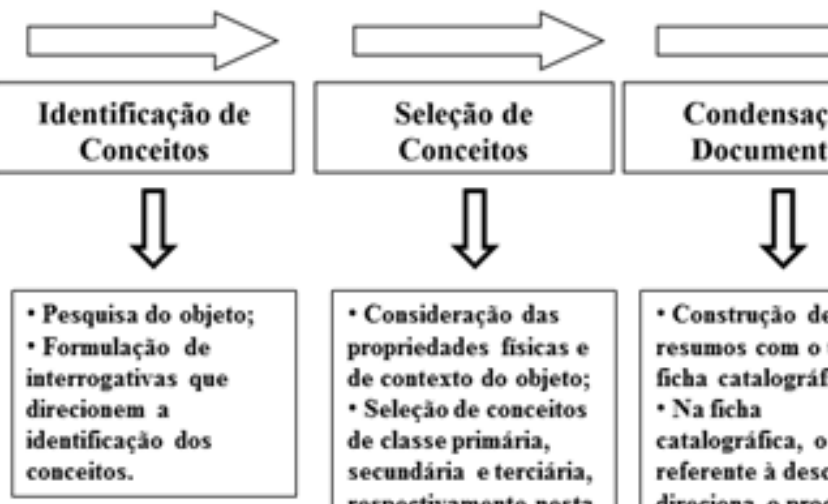

- Construçào de ficha catalográfica; - Na ficha referente à descriçào

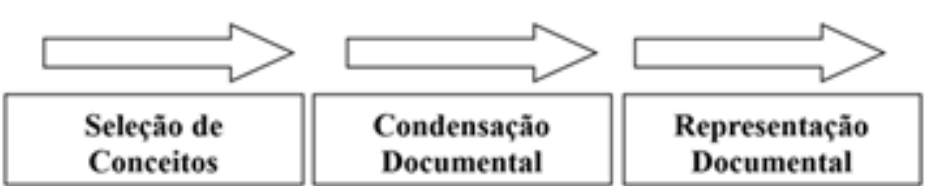

Documental resumos com o uso da

catalográfica, o campo direciona o processo de condensação.

Fonte: Guimarães, Moraes e Guarido (2007) e Padilha (2014)

\section{CONSIDERAÇÕES FINAIS}

O presente estudo analisou como a Análise Documental reflete na Museologia, a partir de uma revisão de conceitos para identificação do tratamento documental no eixo de

\footnotetext{
${ }^{7}$ Considerado como uma Linguagem Documentária, o Thesaurus, ou Tesauro, refere-se à uma relação de termos de domínio, com finalidade da indexação e recuperação em um sistema de recuperação da informação. O Tesauro não é moldado a partir de uma linguagem natural, mas de uma lista de termos correspondentes a um referente (CAMPOS; GOMES, 2006).

${ }^{8}$ O Thesaurus para Acervos Museológicos é uma lista de terminologias referentes a dezesseis categorias de acervos museológicos. Lançado em 1987, este foi construído por Helena Dodd Ferrez e Maria Helena Bianchini.
} 
Documentação Museológica. Deste modo, buscou-se também aproximar as noções de documento museológico, suas propriedades e seu tratamento junto à Ciência da Informação.

A Análise Documental é uma operação que tem por objetivo a representação dos documentos, a partir de um tratamento documental que possa analisar todas as nuances destes, partindo de uma fragmentação, e, por seguinte, a condensação para a representação do conteúdo documental. Com isso, esta operação analítico-sintética está presente em diversos campos científicos, dentre estes, a Museologia.

Ao localizar os conceitos da Análise Documental na Museologia, conclui-se que esta operação está diretamente ligada às práticas de Documentação Museológica. No entanto, as etapas neste âmbito atravessam as características físicas do documento. A Análise Documental na Museologia perpassa, obrigatoriamente, pelas esferas de contexto do objeto, com intuito de representar um conteúdo completo. O conteúdo do documento museológico é composto por propriedades físicas e contextuais, intrínsecas e extrínsecas. As etapas de análise apresentadas na pesquisa reforçam a necessidade do museólogo em identificar diferentes aspectos apresentados por essa documentação, por vezes encontrando eco e interseção em campos como a Biblioteconomia e Ciência da Informação.

A pesquisa conclui que a temática ligada à relação entre a Análise Documental e Documentação Museológica apresenta um promissor campo de estudo, sendo identificado a importância da continuação de pesquisas que lidam sobre o tema, permitindo maior aprimoramento teórico e prático dos museólogos em relação à organização e representação da informação.

\section{REFERÊNCIAS}

BOCCATO, V. R. C.; FUJITA, M. S. L. Discutindo a análise documental de fotografias: uma síntese bibliográfica. Cadernos Bad, n. 2, 2006. Disponível em:

https://www.bad.pt/publicacoes/index.php/cadernos/article/view/794/793. Acesso em: 10 mar. 2019.

CAMARGO-MORO, F. Museu: aquisição e documentação. Rio de Janeiro Livraria Eça Educadora, 1986.

CAMPOS, M. L. A.; GOMES, H. E. Metodologia de elaboração de tesauro conceitual: a categorização como princípio norteador. Perspectivas em Ciência da Informação, v. 11, n. 3, p. 348-359, set./dez. 2006. Disponível em: http://portaldeperiodicos.eci.ufmg.br/index.php/pci/article/download/273/66. Acesso em: 10 mar. 2019.

CERAVOLO, S.; TÁLAMO, F. Os museus e a representação do conhecimento: uma retrospectiva sobre a documentação em museus e o processamento da informação. ENCONTRO NACIONAL DE PESQUISA EM CIÊNCIA DA INFORMAÇÃO, 8., 2007, Salvador. Anais [...] Salvador: ANCIB, 2007. Disponível em: http://www.enancib.ppgci.ufba.br/artigos/GT2--012.pdf. Acesso em: 10 mar. 2019.

CUNHA, I. Análise Documentária. In: SMIT, J. W. (Org.). Análise documentária: a análise da síntese. Brasília: IBICT, 1987, p. 82-86. 
CURY, M. X. Exposição: concepção, montagem e avaliação. São Paulo: Annablume, 2005.

DESVALLÉES, A.; MAIRESSE, F. Conceitos-chaves em museologia, ICOM/Armand Colin/Museu da Língua Portuguesa. São Paulo: Comitê do Conselho Internacional de Museus, 2013.

DODEBEI, V. L. D. Tesauro: linguagem de representação da memória documentária. Rio de Janeiro: Interciência, 2002.

FABBRI, A. Informatização dos Acervos dos Museus como ferramenta de acesso. In: ASSOClAÇÃO CULTURAL DE AMIGOS DO MUSEU CASA DE PORTINARI. Documentação e conservação de acervos museológicos: diretrizes. São Paulo: Associação Cultural de Amigos do Museu Casa de Portinari Governo do Estado de São Paulo / Secretaria do Estado de São Paulo, 2010, p. 26-29.

FERREZ, H. D. Documentação museológica: teoria para uma boa prática. Rio de Janeiro: MINC/IPHAN, 1994.

FUJITA, M. S. L. A leitura documentária na perspectiva de suas variáveis: leitor-textocontexto. DataGramaZero: Revista de Ciência da Informação, v. 5, n. 4, 2004. Disponível em: http://www.brapci.inf.br/index.php/res/download/45204. Acesso em: 10 mar. 2019.

FUJITA, M. S. L.; NARDI, M. I. A.; SANTOS, S. Leitura em análise documental. Transinformação, Campinas, v. 10, n. 3, p. 13-31, 1998.

GIASSON, J. A compreensão na leitura. Lisboa: Asa, 1993.

GUIMARÃES, J. A. C. Abordagens teóricas de tratamento temático da informação (TTI): catalogação de assunto, indexação e análise documental. Ibersid: revista de sistemas de información y documentación, v. 3, p. 105-117, 2009. Disponível em:

https://www.ibersid.eu/ojs/index.php/ibersid/article/view/3730/3491. Acesso em: 10 mar. 2019.

GUIMARÃES, J. A. C.; MORAES, J. B. E.; GUARIDO, M. D. M. Análisis documental de contenido de textos narrativos: bases epistemológicas y perspectivas metodológicas. Ibersid: revista de sistemas de información y documentación, v. 1, p. 93-99, 2007. Disponível em:

https://www.ibersid.eu/ojs/index.php/ibersid/article/view/3267/3028. Acesso em: 10 mar. 2019.

KOBASHI, N. Y. Análise documentária e representação da informação. Informare, Rio de Janeiro, v. 2, n. 2, p. 5-27, 1996.

LARA. M. L. G. Algumas contribuições da semiologia e da semiótica para a análise das linguagens documentárias. Ciência da Informação, Brasília, v. 22, n. 3, p. 223-226, set./dez. 1993. Disponível em: http://revista.ibict.br/ciinf/article/view/480/480. Acesso em: 10 mar. 2019. 
LARA, M. L. G. O unicórnio (o rinoceronte, o ornitorrinco...), a análise documentária e a linguagem documentária. DataGramaZero-Revista de Ciência da Informação, v. 2, n. 6, 2001. Disponível em: http://www.brapci.inf.br/index.php/res/download/44676. Acesso em: 10 mar. 2019.

MENSCH, P. V. Towards a Methodology of Museology. Tese (Doutorado em Filosofia). Faculdade de filosofia. Zagreb, Universidade de Zagreb, 1992.

MOLINA, M. P. Introducción al análisis documental y sus niveles: el análisis de contenido.Boletín de la ANABAD, v. 39, n. 2, p. 323-342, 1989. Disponível em:

https://dialnet.unirioja.es/descarga/articulo/798857.pdf. Acesso em: 10 mar. 2019.

PADILHA, R. C. Documentação museológica e gestão de acervos. Florianópolis: FCC edições, 2014.

REIS, F. C. M. A análise documentária na representação do conhecimento: estudo bibliométrico da produção científica. Dissertação (mestrado em Ciência da Informação). Programa de Pós-Graduação em Ciência da Informação. Belo Horizonte, Universidade Federal de Minas Gerais, 2015.

RIBEIRO, C. Metacognição: um apoio ao processo de aprendizagem. Psicologia: reflexão e crítica, v. 16, n. 1, p. 109-116, 2003. Disponível em:

http://www.scielo.br/pdf/prc/v16n1/16802.pdf. Acesso em: 10 mar. 2019.

ROCHA, C. R. A. Da Pinacoteca ao Museu: historicizando processos museológicos. Dissertação (Mestrado em Museologia). São Paulo, Universidade de São Paulo, 2014.

SILVA, G. B. A importância da preservação, conservação e tratamento dos registros arquivísticos da Comunicação-UFRN. Múltiplos Olhares em Ciência da Informação, v. 3, n. 2, 2014.

YASSUDA, S. N. Documentação museológica: uma reflexão sobre o tratamento descritivo do objeto no Museu Paulista. Dissertação (Mestrado em Ciência da Informação). Faculdade de Filosofia e Ciências. Marília, Universidade Estadual Paulista, 2009. 